\section{Analisis dan Perancangan Sistem Informasi Promosi Berbasis Web Bagi UKM di Wilayah Kota Bogor}

\author{
Web-Based \\ Promotional \\ Information System \\ Design for SMEs
}

\author{
Edi Nurachmad dan Septian Cahyadi \\ Program Studi Teknologi Informasi, Institut Bisnis dan Informatika Kesatuan \\ Bogor, Indonesia \\ E-Mail: e.nurachmad@ibik.ac.id, scahyadi@ibik.ac.id
}

Submitted: MARET 2021

Accepted: JUNI 2021

\begin{abstract}
Dimasa pandemi seperti sekarang ini, transaksi pembelian dan penjualan terhadap produk yang ditawarkan susah dilaksanakan karena adanya pembatasan interaksi sosial diantara manusia, yang mengakibatkan UKM sulit untuk menjual produk-produknya. Perkembangan teknologi informasi, terutama internet tentunya bisa dijadikan suatu media untuk mengatasi masalah tersebut. Keberadaan suatu sistem informasi berbasis website, diharapkan dapat membantu pemasaran terutama dalam penyampaian informasi produk dan harga secara detail kepada konsumen.

Melihat kondisi seperti itu, maka perlu adanya suatu sistem informasi yang komunikatif berbasis web yang tentunya diharapkan dapat menyelesaikan permasalahan terutama penyampaian informasi produk-produk unggulan UKM di kota Bogor.
\end{abstract}

Kata Kunci : Internet, UKM, Market Place, Sistem Informasi

\section{PENDAHULUAN}

Usaha Kecil Menengah (UKM) adalah usaha yang memiliki potensi besar dalam pembanguanan ekonomi Indonesia. Peranan UKM sangatlah penting, UKM banyak sekali menciptakan lapangan kerja baru, unit-unit kerja baru bahkan menciptakan tenaga-tenaga kerja baru, yang akhirnya dapat meningkatkan pendapatan rumah tangga, pernan UKM inilah yang membantu negara atau pemerintah dalam memajukan perekonomian masyarakat.

Pada krisis moneter tahun 1998, UKM sudah terbukti mampu bertahan pada situasi krisis global yang melanda dunia pada saat itu. UKM hadir menjadi salah satu solusi sistem perekonomian yang sehat, bahkan sama sekali tidak terkena dampak krisis. Namun dari sisi dukungan informasi terhadap produk-produk UKM, perlu adanya perhatian khusus sehingga pelaku UKM memiliki link bisnis yang terarah dengan daya saing usaha yaitu berupa jaringan pasar.

UKM merupakan sektor yang penting namun, dalam proses pemasarannnya sulit untuk menembus pasar yang lebih luas hanya wilayah lokal saja, hal ini dikarenakan sebagian besar pelaku UMK memiliki pendidikan rendah dan memiliki kegiatan usaha yang kecil dan masih tradisional.

Dimasa pandemi covid-19, dimana pertumbuhan ekonomi melambat, hinggga pada kuartal I 2020 mencapai 2,97\%, hal ini berdampak pada pertumbuhan ekonomi di sektor usaha mikro, kecil dan menengan (UMKM). Di era digital ini, pelakuk UKM tentunya perlu perhatian, juga melakukan transformasi dalam proses bisnisnya agar dapat bertahan. Belum semua pelaku UKM memanfaatkan teknologi terutama internet untuk memasarkan produknya, yang sebenarnya kegiatan ini bisa dilakukan melaui media sosial atau marketplace.

\section{JIMKES}

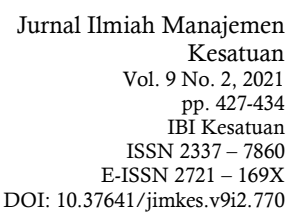


Web-Based

Promotional

Information System

Design for SMEs

428
Pandemi telah memaksa dan mampu menggeser perilaku masyarakat dalam segala aktivitasnya, termasuk aktivitas melakukan jual beli yang dulu lebih banyak secara offlline, sekarang dominan ke dalam sistem online. Hal ini bisa menjadi peluang bagi pelakuk UKM agar bisa bertahan di tengah pandemi.

Bogor merupakan kota jasa, kegiatan masyarakat merupakan penggerak utama dari semua aktivitas usaha dan bisnis, ketika aktivitas kegiatan masyarakat dibatasi, maka ruang gerak masyarakat sebagai konsumen akan semakin sempit, ini berimbas pada aktivitas usaha dan bisnis pun kian terbatas atau stagnan.

Pelaku UKM di kota Bogor, dirasakan cukup banyak dan didalamnya memiliki berbagai macam jenis-jenis produk yang diperjual belikan, namun dalam kondisi pandemi sekarang ini penjualan produk dari pelaku-pelaku UKM mengalami kendala. Promosi produk dengan metode konvensional misalnya membuka cabang baru, melakukan pameran, pembuatan dan penyebaran brosur dan sebagainya, tentunya membutuhkan biaya yang cukup tinggi.

Saat ini Internet adalah media yang banyak dimanfaatkan oleh dunia bisnis untuk meningkatkan kehidupan masyarakat, penggunaan internet di Indonesia saat ini meningkat secara drastis selama beberapa tahun. Website yang merupakan sebuah kumpulan halaman pada suatu domain di internet yang dibuat dengan tujuan tertentu dan dapat diakses secara luas melalui home page menggunakan sebuah browser. Keberadaan suatu website inilah yang diharapkan dapat membantu pemasaran terutama dalam bidang promosi serta penyampaian informasi produk dan harga secara detail kepada konsumen.

Berdasarkan masalah tersebut diatas, untuk itu kami menyusun proposal ini untuk membahas tentang bagaimana membuat pemasaran usaha-usaha UKM terkoneksi secara global. Hal ini bisa melalui pemanfaatan jaringan internet dengan membuat website sebagai media informasi dan pemasaran bagi produk-produk UKM di kota Bogor..

\section{METODE PENELITIAN}

Metode yang dilakukan dalam pengembangan sistem informasi rekayasa perangkat lunak menggunakan metode sebagai berikut:

a. Analisa sistem, tahap pengumpulan data dari pengguna dalam hal ini adalah pelaku UKM terhadap kebutuhan sistem informasi apa yang di butuhkan untuk pemasaran online produknya.

b. Desain sistem, tahap pembuatan desain sistem informasi pemasaran online (website) untuk produk-produk UKM.

c. Implementasi dan pengujian sistem, tahap ini dimulai dari menuliskan kode-kode bahasa pemrograman untuk pembuatan sistem informasi pemasaran online (website) untuk produk-produk UKM. Kemudian dilakukan pengecekan terhadap kesalahan (error) atau kondisi tidak normal pada sistem pemasaran online produk.

\section{HASIL DAN PEMBAHASAN}

\section{A. Analisis Sistem}

Dengan mengidentifikasi dan menganalisis metode pengenalan produk yang dilakukan oleh pelaku UMKM selama ini, pengenalan produk dilakukan dengan mengikuti pameran-pameran dan bazar yang dilakukan oleh pemerintah setempat, atau bahkan melalui pembuatan dan penyebaran brosur melalui media online seperti instagram atau group whatsApp. Pengenalan produk seperti ini tentunya masih mempunyai kelemahan, karena informasi dari produk tersebut tidak terseber secara luas dan informasi tentang produk-produk yang ada juga tidak memadai, sehingga belum banyak masyarakat yang mengetahui tentang produk-produk yang telah di produksi oleh UKM-UKM di kota Bogor. Oleh Karena itu, perlu diatasi dengan menyediakan informasi 
promosi tentang produk-produk dengan menggunakan media informasi berbasis website, sehingga sistem informasi yang akan dikembangkan nantinya akan mempermudah informasi promosi dari produk-produk yang ada agar lebih diketahui oleh masyarakat secara luas tidak hanya dari wilayah Bogor saja bahkan mungki secara global.

\section{B. Desain sistem}

\section{Diagram Usecase}

Diagram usecase dititik beratkan pada kebutuhan fungsi-fungsi apa saja yang ada pada sistem dan siapa (user) yang menggunakan funsi tersebut. Diagram usecase dapat digambarkan sebagai berikut:

Web-Based

Promotional

Information System

Design for SMEs

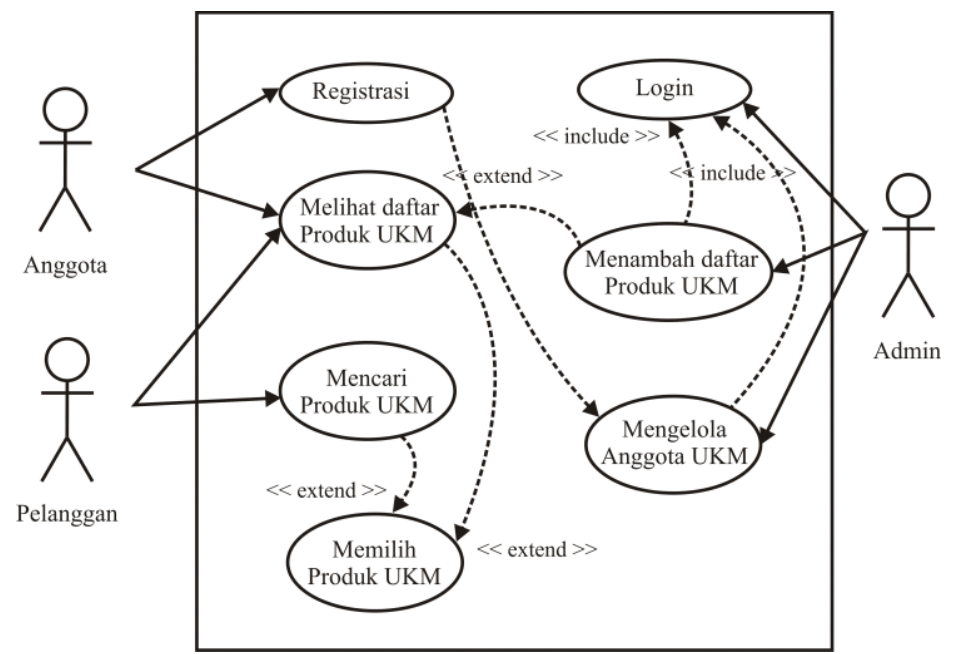

Deskripsi user pada sistem terdiri dari tiga aktor yang terdiri dari admin, anggota dan pelanggan.

\section{Deskripsi Aktor}

\begin{tabular}{|l|l|l|}
\hline No & \multicolumn{1}{|c|}{ Aktor } & \multicolumn{1}{c|}{ Deskripsi Aktor } \\
\hline 1. & Admin & $\begin{array}{l}\text { Orang yang memiliki hak akses mengelola sistem dalam ini } \\
\text { seperti menambahkan daftar produk umkm, memperbaharui } \\
\text { dan menyebarkan informasi produk kepada pelanggan. }\end{array}$ \\
\hline 2. & Anggota & $\begin{array}{l}\text { Orang yang terdaftar sebagai anggota dari sistem yang } \\
\text { mendaftarkan usahanya pada sistem, dan dapat memasarkan } \\
\text { produk-produk yang dihasilkannya oleh sistem. }\end{array}$ \\
\hline 4. & Pelanggan & $\begin{array}{l}\text { Orang yang mencari informasi tentang produk-produk umkm, } \\
\text { dan melakukan pesanan terhadap produk yang akan dibeli. }\end{array}$ \\
\hline
\end{tabular}

Deskripsi use case atau kebutuhan fungsional pada sistem yang berinteraksi dengan aktor.

\section{Deskripsi Usecase}

\begin{tabular}{|l|l|l|}
\hline No & \multicolumn{1}{|c|}{ Use Case } & \multicolumn{1}{c|}{ Deskripsi Usecase } \\
\hline 1. & Registrasi & $\begin{array}{l}\text { Pengunjung dapat melakukan pendaftaran untuk menjadi } \\
\text { anggota pada sistem }\end{array}$ \\
\hline 2. & $\begin{array}{l}\text { Melihat Daftar } \\
\text { Produk UKM }\end{array}$ & $\begin{array}{l}\text { Pelanggan dapat melihat produk-produk yang ditawarkan } \\
\text { pada sistem dan melakukan pesanan kepada pemilik produk }\end{array}$ \\
\hline 3. & $\begin{array}{l}\text { Mencari Produk } \\
\text { UKM }\end{array}$ & $\begin{array}{l}\text { Pelanggan dapat melakukan penelusuran berdasarkan } \\
\text { kategori produk yang akan dicari. }\end{array}$ \\
\hline 4. & $\begin{array}{l}\text { Memilih produk } \\
\text { UKM }\end{array}$ & $\begin{array}{l}\text { Pelanggan dapat melihat produk yang dipilihnya dan dapat } \\
\text { langsung melakukan pesanan kepada pemilik produk. }\end{array}$ \\
\hline
\end{tabular}


Web-Based

Promotional

Information System

Design for SMEs

\section{Diagram Activity}

Diagram activity digunakan untuk menggambarkan alur kejadian dalam sistem, bagaimana aktivitasnya dalam sistem. Berikut gambar diagram activity menambahkan daftar produk pada sistem.

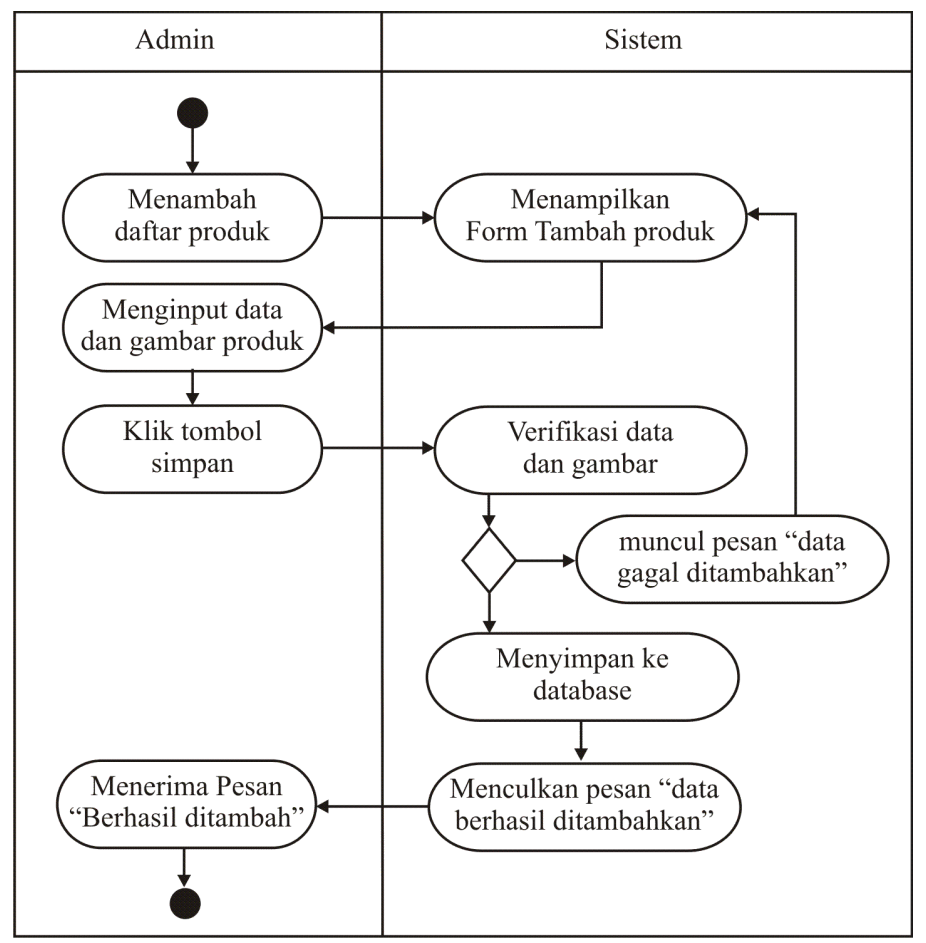


3. ERD Database

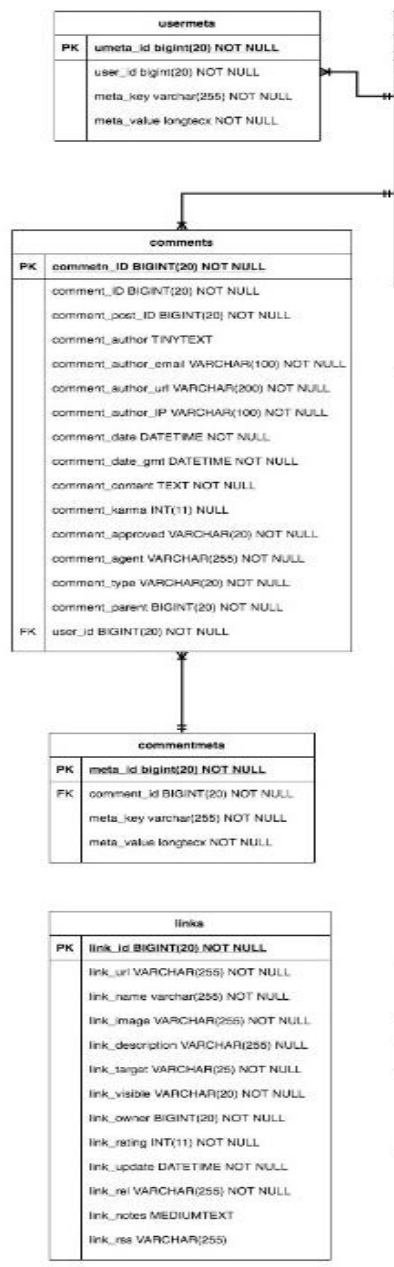

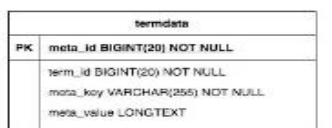
mose vesur LONGTDXT

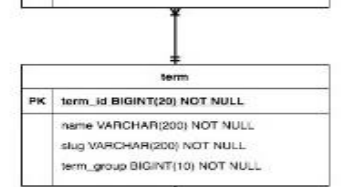

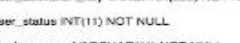
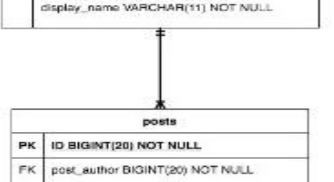

pose author BISINT:Cos) NOT $n$

port cale DARETIME NaT NULL

POLL DAR G GTC OATETME NOT NUL

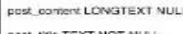

Fose Hin TExT NoT NUL

DUD EXcerse TEXT NOT NULL

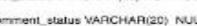

Fing san: VAFCHAEZZII NULL

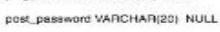

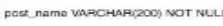

10. PRg TEXT NULL

finged TEXT VUL

DES MOdXad DATETTME NOT NUU

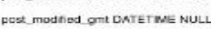

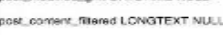

puth parent BISINT (20) NULL

Fü VAACHAR(2S5) NOT NULL

nert_. Odde INT(11) NOT NULL

pese mire tyes WaACHaA (100) NoT

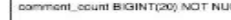

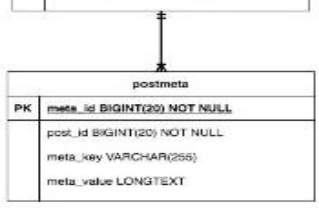

4. Desain layout antamuka.

Layout terdiri dari lima bagian yaitu menu navigasi, header, content, submenu dan menu search. Keterangan sebagai berikut :

- Menu: navigasi, isi keseluruhan menu

- Header: berisi logo dan nama instansi

- Content: berisi informasi halaman produk-produk UKM yang ada pada sistem.

- SubMenu: Informasi lainnya.

- Footer: berisi informasi keterangan website.

\begin{tabular}{|c||c|}
\hline Header & Menu \\
\hline \hline & Menu search \\
\cline { 2 - 2 } & \\
Sub Menu & \\
& \\
& \\
& \\
& \\
\hline
\end{tabular}

\section{Implementasi Sistem}

Implementasi sistem ini menggunakan jaringan komputer berbasis client-server. Komputer client digunakan sebagai antarmuka bagi pengguna untuk dapat mengakses 
Web-Based

Promotional

Information System

Design for SMEs

432 data, dengan melakukan installasi berupa web browser. Dari penggunaan web browser yang sudah dicoba adalah mozilla firefox, google crome dan internet explorer, dan hasilnya dari segi tampilan cukup optimal dan fungsi dari sistem berjalan dengan baik.

Berikut halaman utama dimana pelanggan dapat melihat informasi produkproduk UKM apa yang ada pada sistem, dapat diakses pada halaman pojokukm.ibik.ac.id.

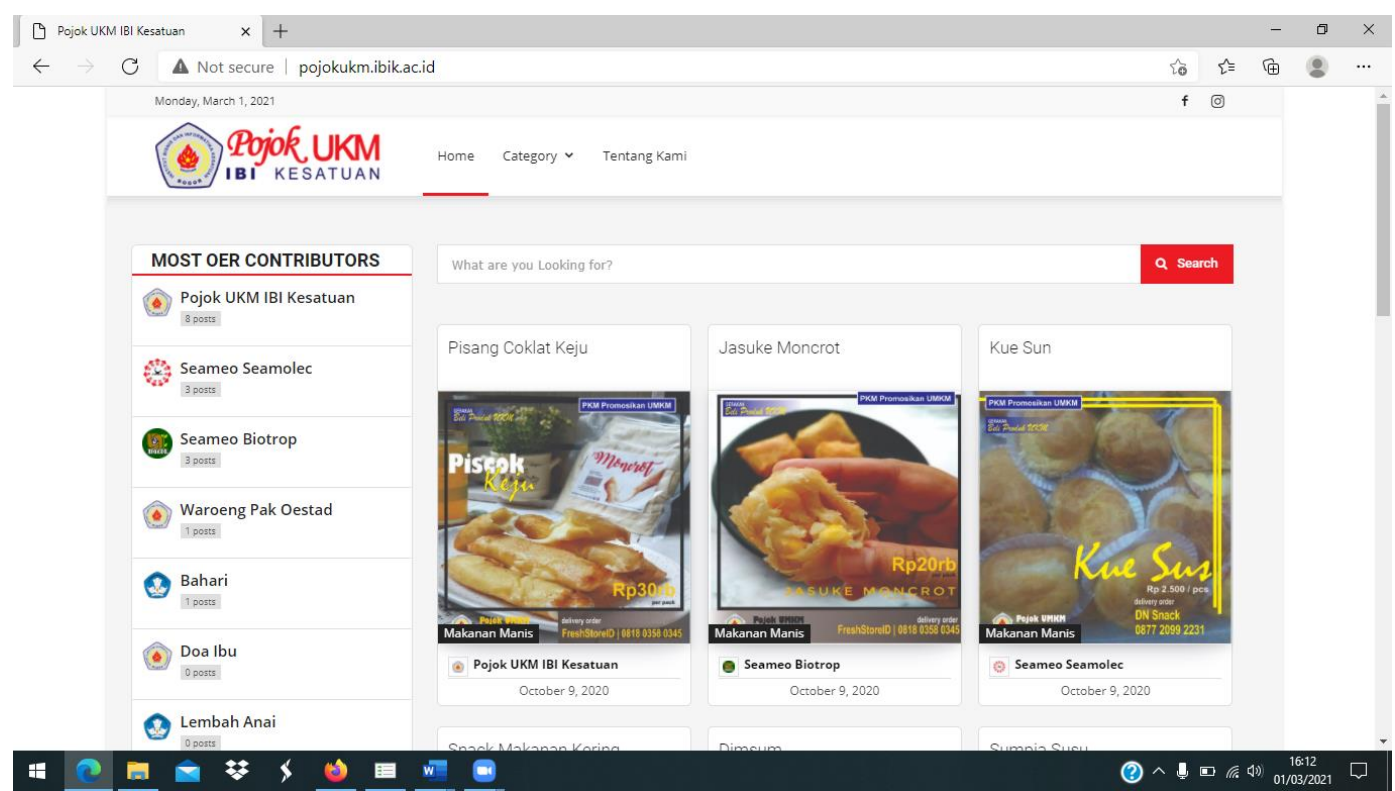

Halaman untuk pencarian produk-produk UKM

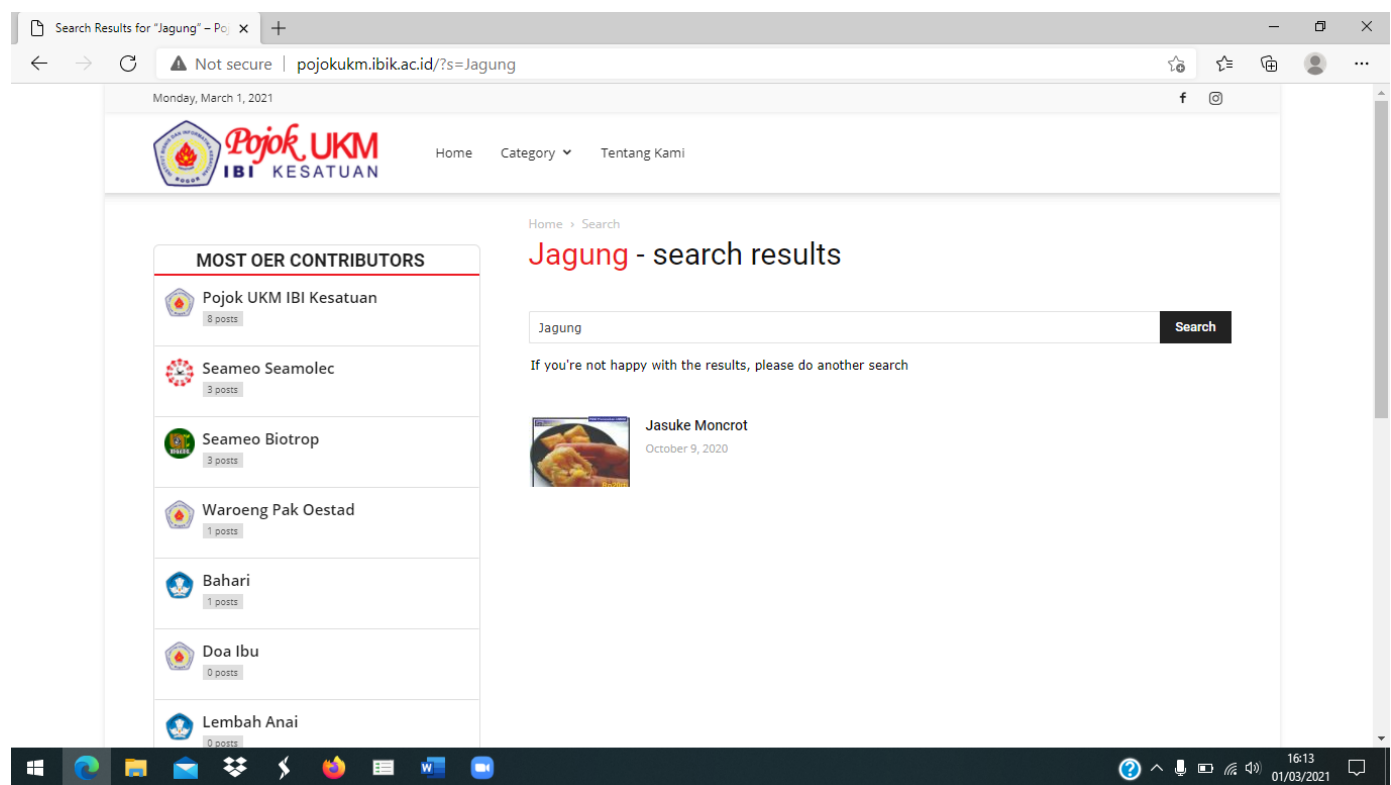




\section{PENUTUP}

Di Bogor banyak pengusaha yang yang menghasilakn memiliki berbagai macam jenis produk UKM, namun dalam situasi pandemi sekarang ini, keterbatasan dalam hal penjualan dan mempromosikan produknya menjadi masalah utama yang dihadapi oleh para pengusaha UKM. Metode penjualan secara konvensional, sulit dilakukan juga dan memerlukan biaya tinggi, misalnya membuka cabang baru, ikut pameran, pembuatan dan penyebaran brosur dan sebagainya.

Pembuatan sistem market place berbasis website ini diharapkan memberikan solusi mengenai permasalahan yang terjadi bagi para pengusaha UKM, dimana Pelanggan dalam hal ini masyarakat akan mudah memperoleh informasi tentang produk UKM dan sekaligus mempromosikan produk-produk yang dihasilkan oleh para pengusaha UKM di wilayah Bogor.

\section{REKOMENDASI}

Berdasarkan kesimpulan diatas, maka rekomendasi yang dapat disampaikan adalah sebagai berikut:

1. Aplikasi ini masih perlu dikembangkan lagi, penelitian berikutnya diharapkan akan menambahkan modul-modul lain terutama terkait dengan penambahan fitur-fitur transaksi jual beli yang dilakukan baik oleh penjual maupu dengan pembeli.

2. Penambahan sistem informasi geografis bisa dilakukan guna mengetahui lokasilokasi dimana pelaku-pelaku UKM tersebut berada

\section{DAFTAR PUSTAKA}

Jogiyanto, H.M., 2005, Analisa dan Desain Sistem Informasi: Pendekatan Terstruktur Teori dan Praktik Aplikasi Bisnis, ANDI, Yogyakarta.

M. Yusuf dan Herry Mulyono, 2018. Analisis dan Perancangan Sistem Informasi Promosi Berbasis Web Pada Asosiasi UMKM Muaro Jambi. Jurnal Manajemen Sistem Informasi, Vol 3, No. 1, Maret 2018, p. 845-855.

Mariana Kristiyanti dan Lisda Rahmasari, Sistem Informasi Berbasis Web Produk Unggulan Usaha Mikro Kecil Dan Menengah (Umkm) Di Kota Semarang. Prosiding Seminar Nasional Multi Disiplin Ilmu \& Call For Papers Unisbank (Sendi_U) Kajian Multi Disiplin Ilmu untuk Mewujudkan Poros Maritim dalam Pembangunan Ekonomi Berbasis Kesejahteraan Rakyat, p. 1-12.

Novi Puji Lestari, 2020. Masa Depan UMKM di tengan Covid-19, post on : 2707 2020. https://www.harianbhirawa.co.id/masa-depan-umkm-di-tengah-covid-19.

Tona Aurora Lubis dan Junaidi, 2016. Pemanfaatan Teknologi Informasi pada Usaha Mikro Kecil dan Menengah di Kota Jambi. Jurnal Perspektif Pembiayaan dan Pembangunan Daerah Vol. 3 No. 3, Januari-Maret 2016, p. 163-174.

Tubagus Riko Rivanthio dan Abdur Razak, 2019. Perancangan Sistem Informasi Umkm Dan Kelompok Tani Bunga Di Kecamatan Sukaresmi Kabupaten Cianjur. TEMATIK - Jurnal Teknologi Informasi Dan Komunikasi Vol. 6, No. 2 Desember 2019, p. 174-183.

Wiwit Agus Trianto, 2017. Analisa dan Perancangan Sistem Informasi Penjualan Online untuk Meningkatkan Pemasaran Produk UMKM Kerajinan Tas. Indonesian Journal on Networking and Security - Volume 6 No 3, p. 63-67. 